\title{
ORIGINAL ARTICLE Relationships between wheelchair skills, wheelchair mobility and level of injury in individuals with spinal cord injury
}

\author{
V Lemay ${ }^{1,2}$, F Routhier ${ }^{1,2}$, L Noreau $^{1,2}$, SH Phang ${ }^{3}$ and KA Martin Ginis ${ }^{3}$
}

Study design: Cross-sectional.

Objectives: To describe the manual wheelchair (MWC) skill profiles of experienced MWC users with spinal cord injury and their wheeled mobility (distance and speed) while considering their level of injury and age.

Setting: Rehabilitation centers, participant's home and the community.

Methods: MWC skills were evaluated using the wheelchair skills test (WST) and wheeled mobility data were collected in the participants' own environment over a 7-day period, using a Cateye cycle computer (VELO 8). A total of 54 participants took part in the study.

Results: The mean total performance score of the sample on the WST was $80.7 \pm 11.8 \%$, with a significant difference between participants with tetraplegia (C4-C8) and those with low-level paraplegia (T7-L2) $(P<0.01)$. The average daily distance covered was $2.5 \pm 2.1 \mathrm{~km}$ at $1.7 \pm 0.9 \mathrm{~km} \mathrm{~h}^{-1}$, with no significant difference between participants with paraplegia and those with tetraplegia (wheeled distance: $P=0.70$; speed: $P=0.65$ ). Significant relationships were found between MWC skills and daily wheeled distance $(r=-0.32, P<0.05)$, but the correlation between these variables did not remain significant when controlling for age (partial $r=0.26, P=0.07$ ).

Conclusion: These results suggest that the level of injury is related to MWC skills but not wheeled mobility. MWC skills are related to greater wheeled distance, but to a lesser extent when controlling for age.

Spinal Cord (2012) 50, 37-41; doi:10.1038/sc.2011.98; published online 20 September 2011

Keywords: wheelchair; wheelchair skills; mobility; spinal cord injury

\section{INTRODUCTION}

Mobility is perceived as one of the most restricted domains of social participation after spinal cord injury (SCI). ${ }^{1}$ Mobility is defined as a life habit where a person has to go from one place to another with or without the use of transportation. ${ }^{2}$ Knowing that the accomplishment of many valued activities and social roles is highly wheelchair (WC) dependent in individuals with SCI, limitations in mobility can considerably restrict opportunities to participate in social activities. Moreover, WC users with SCI face many environmental barriers, in addition to other types of challenges that potentially restrict social participation. There is evidence that the personal characteristics of manual wheelchair (MWC) users with SCI (for example, age, pain, level of injury, depression) and the characteristics of the MWC (for example, MWC configuration) reduce their capacity to propel their MWC, ${ }^{3-5}$ with a potential impact on community mobility. ${ }^{1}$ Greater ability to use a MWC and transportation is essential after SCI and it could, for example, enhance the likelihood of returning to work and other vocational activities. ${ }^{67}$ Recent findings suggest that MWC skills, defined as the ability to maneuver the MWC, ${ }^{8}$ are related to social participation 1 year after discharge, ${ }^{9}$ but there is still no evidence regarding long-term factors affecting mobility at home and in the community of MWC users with SCI, and how MWC skills are related to the accomplishment of activities and social roles more than 1 year post discharge.

A large proportion of people with SCI require a MWC for their mobility $(50-80 \%),{ }^{10}$ and should receive proper training to ensure optimal MWC skills at rehabilitation discharge. However, there does not seem to be any standardized or optimal MWC training in rehabilitation centers. A recent study showed that only $17-18 \%$ of WC users (not SCI-specific) received formal WC skills training. ${ }^{11,12}$ One could hypothesize that evidence of a significant contribution of MWC skills to long-term community participation would encourage rehabilitation settings to more systematically include such training during rehabilitation. To date, no data are available to validate this hypothesis. In the past, training protocols, such as the Wheelchair Skills Training Program (WSTP) ${ }^{8}$ demonstrated significantly better results than regular training programs for improving WC skills, ${ }^{13-15}$ but there is no indication that such an improvement can translate into greater social participation.

The primary objective of this study was to describe the MWC skill profiles of experienced users with SCI and their mobility at home and in the community, in terms of wheeled distance and speed, while considering their level of injury, age and MWC experience. We hypothesized that a lower level of injury, more MWC experience

\footnotetext{
${ }^{1}$ Centre interdisciplinaire de recherche en réadaptation et intégration sociale (CIRRIS), Institut de réadaptation en déficience physique de Québec (IRDPQ), Québec, Canada; ${ }^{2}$ Faculté de médecine, Département de réadaptation, Université Laval, Québec, Canada and ${ }^{3}$ Department of Kinesiology, McMaster University, Hamilton, Ontario, Canada Correspondence: Dr F Routhier, Centre interdisciplinaire de recherche en réadaptation et intégration sociale (CIRRIS), Institut de réadaptation en déficience physique de Québec, 525, boulevard Wilfrid-Hamel est, Québec, Canada G1M 2 S8.

E-mail: Francois.Routhier@rea.ulaval.ca

Received 17 February 2011; revised 1 July 2011; accepted 22 July 2011; published online 20 September 2011
} 
and younger age would be associated with greater MWC skills and mobility, at home and in the community. Our secondary objective was to test the hypothesis that better MWC skills would be associated with greater wheeled mobility. This study is the first step in a research program aimed at demonstrating the importance of improving MWC skills to ensure optimal social participation.

\section{MATERIALS AND METHODS}

\section{Design}

A cross-sectional study design was used for this study. Ethical approval was obtained from the local rehabilitation institutes and universities' ethics boards. All applicable institutional and government regulations concerning the ethical use of human volunteers were followed during the research.

\section{Sample}

Participants were recruited with the support of two Canadian rehabilitation centers, the Institut de réadaptation en déficience physique de Québec (IRDPQ) in Québec City $(n=29)$ and the Toronto Rehabilitation Institute (TRI) in Toronto $(n=25)$. Participants were recruited based on the following criteria: at least 12 months of MWC use before recruitment, MWC user (self-reported average daily use $\geqslant 4 \mathrm{~h}$ ), 18 years of age or older, no other diagnosis (for example, multiple sclerosis) or cognitive impairment. After receiving all information about the project, participants completed an informed consent form.

\section{WC skills}

MWC skills were evaluated using the wheelchair skills test (WST) version $4.1 .^{8}$ Measurement properties of the WST were evaluated, and showed good reliability and validity. ${ }^{16} \mathrm{~A}$ recent systematic review supports its use in the SCI population. ${ }^{17}$ The WST is a standardized evaluation method (obstacle course) used to objectively evaluate a representative set of WC skills for manual or powered WC users, as well as WC users' caregivers. We used the MWC user form (WST-M-WCU) that contains 32 skills. Each skill was evaluated on a performance (pass/fail) and a safety (safe/unsafe) scale. A total performance score and total safety score were calculated for the WST (from 0 to $100 \%$ ). Performance of the skill is considered 'pass' only if it is done safely. ${ }^{8}$ For this project, the total safety score was not reported because almost all of the participants (83\%) had a score of $100 \%$ for the safety subscale. The skills mostly rated as 'unsafe' were the ones related to going up and down stairs $(26 \%$ of all unsafe scores), going up and down curbs ( 5 and $15 \mathrm{~cm})(35 \%$ of all unsafe scores), and folding/unfolding the MWC (13\% of all unsafe scores). The lowest total safety score was $87.5 \%$. This could be because the people recruited had a long-standing SCI and extensive MWC experience, with good knowledge of obstacles they can overcome safely and those they cannot.

\section{Wheeled distance and speed}

Wheeled distance and speed were evaluated using a commercial cycle computer system (VELO 8: Cateye, Boulder, CO, USA; Figures 1a and b). This system is composed of a sensor, magnets and a 'computer' in which mobility data are collected. To collect data at low speeds (for example, moving around inside the house), we installed three or four magnets on the spokes of the WC depending on the type of wheel. We were able to collect data from speeds around $0.80 \mathrm{~km} \mathrm{~h}^{-1}\left(0.22 \mathrm{~m} \mathrm{~s}^{-1}\right)$. We asked participants to keep this system on their WC for a 7-day data-collection period and to fill out a data-cycle computer logbook every day (cycle computer values only). At the end of the 7-day datacollection period, the cycle computer logbooks were retrieved and reviewed with the participants. Qualitative information was collected based on participants' oral feedback to complement numerical values in the logbook. Wheeled mobility data recorded included the number of magnets on the WC spokes.

\section{Personal and injury characteristics}

We used an in-house demographic questionnaire to collect information on age, gender, level of injury, time since injury, MWC experience, education, marital and employment status (see Table 1).

\section{Statistics}

Descriptive statistics were used to characterize the sample and mobility variables (mean, standard deviation and frequency). Differences between participants with
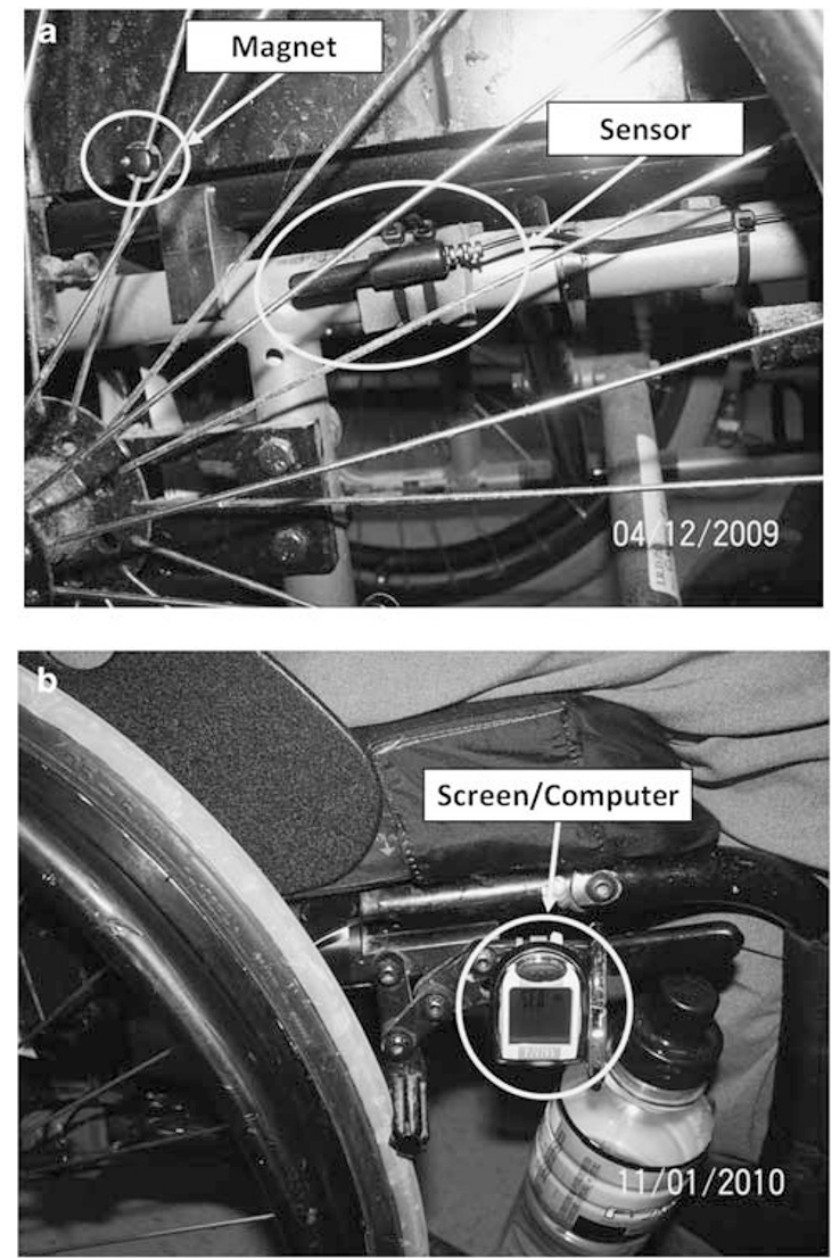

Figure 1 Cycle computer installation. (a) Magnets and sensor on a MWC. (b) Cycle computer screen.

different levels of injury (tetraplegia, high and low paraplegia) regarding personal characteristics, total performance score on the WST and wheeled mobility were analyzed using ANOVA and Bonferroni post-hoc tests. These tests were also used to identify differences in the total performance score on the WST and wheeled mobility for participants with different personal characteristics (gender, employment status, marital status and education). Pearson's correlations (and partial correlations) were used to depict relationships between variables of interest.

\section{RESULTS}

\section{Descriptive statistics}

Table 1 presents the characteristics of the 54 participants in our study (29 from Québec City and 25 from Toronto). Mean age was $46.7 \pm 12.8$ years and mean MWC experience was $16.0 \pm 11.2$ years. Three-quarters of the participants $(75.9 \%)$ were male and just over half $(55.6 \%)$ had low paraplegia.

\section{MWC skills and mobility profile}

The mean total performance score on the WST was $80.7 \pm 11.8$, with $55.6 \%$ of the participants scoring over $80 \%$, which is empirically considered the cut-off for distinguishing people with advanced MWC skills (mainly skills required to control wheelies). Only $28.6 \%$ of the participants with tetraplegia (4 out of 14) reached or exceeded the $80 \%$ cut-off, suggesting advanced MWC skills. Table 2 presents the relationship between level of injury and WST total performance score, 
Table 1 Sample characteristics

\begin{tabular}{|c|c|}
\hline Descriptors & All participants $(\mathrm{n}=54$ \\
\hline \multicolumn{2}{|l|}{ Mean age (years) } \\
\hline Mean \pm s.d. & $46.7 \pm 12.8$ \\
\hline Min-max & $24-79$ \\
\hline \multicolumn{2}{|l|}{ MWC experience (years) } \\
\hline Mean \pm s.d. & $16.0 \pm 11.2$ \\
\hline Min-max & $1-40$ \\
\hline \multicolumn{2}{|l|}{ Site } \\
\hline Québec City & $29(53.7 \%)$ \\
\hline Toronto & $25(46.3 \%)$ \\
\hline \multicolumn{2}{|l|}{ Gender } \\
\hline Male & $41(75.9 \%)$ \\
\hline Female & $13(24.1 \%)$ \\
\hline \multicolumn{2}{|l|}{ Level of injury } \\
\hline Tetraplegia (C4-C8) & $14(25.9 \%)$ \\
\hline High paraplegia (T1-T6) & $10(18.5 \%)$ \\
\hline Low paraplegia (T7-L2) & $30(55.6 \%)$ \\
\hline \multicolumn{2}{|l|}{ Severity of injury } \\
\hline Complete & $27(50.0 \%)$ \\
\hline Incomplete & $27(50.0 \%)$ \\
\hline \multicolumn{2}{|l|}{ Education } \\
\hline Elementary & $7(13.0 \%)$ \\
\hline High school & $20(37.0 \%)$ \\
\hline College & $12(22.2 \%)$ \\
\hline University & $11(20.4 \%)$ \\
\hline Graduate studies & $4(7.4 \%)$ \\
\hline \multicolumn{2}{|l|}{ Marital status } \\
\hline Single & $24(44.4 \%)$ \\
\hline Common law & $7(13.0 \%)$ \\
\hline Married & $16(29.6 \%)$ \\
\hline Divorced & $6(11.1 \%)$ \\
\hline Widowed & $1(1.9 \%)$ \\
\hline \multicolumn{2}{|l|}{ Occupational status } \\
\hline Not employed & $34(64.2 \%)$ \\
\hline Employed & $19(35.8 \%)$ \\
\hline \multicolumn{2}{|l|}{ Ethnicity } \\
\hline White & $39(72.2 \%)$ \\
\hline Native Canadian & $5(9.3 \%)$ \\
\hline Black & $3(5.6 \%)$ \\
\hline Asian & $4(7.4 \%)$ \\
\hline Other & $3(5.6 \%)$ \\
\hline
\end{tabular}

and wheeled mobility at home and in the community. A significant difference was observed in the mean total performance score on the WST $(\mathrm{F}(2,51)=5.91, P<0.01)$. Bonferroni post-hoc tests showed differences between participants with tetraplegia (C4-C8) and those with low-level paraplegia (T7-L2) $(M=72.1 \pm 7.9$ and $84.0 \pm 12.4$, $P<0.01)$. No significant differences were found between people with tetraplegia, those with high paraplegia and those with low paraplegia for wheeled mobility at home and in the community (distance:
Table 2 Influence of level of injury on MWC skills and wheeled mobility at home and in the community

\begin{tabular}{|c|c|c|c|c|}
\hline Descriptors & All participants & $\begin{array}{l}\text { Tetraplegia } \\
\text { (C4-c8) }\end{array}$ & $\begin{array}{c}\text { High paraplegia } \\
\text { (T1-T6) }\end{array}$ & $\begin{array}{c}\text { Low paraplegia } \\
(T 7-L 2)\end{array}$ \\
\hline MWC skills & $(n=54)$ & $(n=14)$ & $(n=10)$ & $(n=30)$ \\
\hline \multicolumn{5}{|c|}{ WST total performance score (\%) } \\
\hline Mean \pm s.d. & $80.7 \pm 11.8$ & $72.1 \pm 7.9 *$ & $82.8 \pm 9.1$ & $84.0 \pm 12.4^{*}$ \\
\hline $\begin{array}{l}\text { Wheeled mobility } \\
\text { (cycle computer) }\end{array}$ & $(n=50)$ & $(n=13)$ & $(n=10)$ & $(n=27)$ \\
\hline \multicolumn{5}{|c|}{ Wheeled distance/day $(\mathrm{km})^{\mathrm{a}}$} \\
\hline Mean \pm s.d. & $2.5 \pm 2.1$ & $2.4 \pm 2.5$ & $2.2 \pm 1.5$ & $2.6 \pm 2.2$ \\
\hline Median & 1.7 & 1.6 & 1.7 & 1.9 \\
\hline Min-max & $0.3-10.1$ & $0.6-9.9$ & $1.1-6.2$ & $0.4-10.1$ \\
\hline \multicolumn{5}{|c|}{ Wheeled speed/day $\left(\mathrm{km} \mathrm{h}^{-1}\right)$} \\
\hline Mean \pm s.d. & $1.7 \pm 0.9$ & $1.5 \pm 0.8$ & $1.5 \pm 0.4$ & $1.9 \pm 1.0$ \\
\hline Median & 1.6 & 1.6 & 1.4 & 2.0 \\
\hline Min-max & $0.6-5.0$ & $0.6-3.3$ & $1.0-2.4$ & $0.6-5.0$ \\
\hline
\end{tabular}

Abbreviations: MWC, manual wheelchair; WST, wheelchair skills test.

aANOVA test was performed on a transformation of the variable $\left(\log _{10}\right)$ to meet normality assumption.

*Significant difference between groups $(P<0.05)$.

Table 3 Relationship between MWC skills and wheeled mobility at home and in the community

\begin{tabular}{lccccc}
\hline & $\begin{array}{c}\text { WST total } \\
\text { performance } \\
\text { score (\%) }\end{array}$ & $\begin{array}{c}\text { Wheeled } \\
\text { distance per } \\
\text { day }(\mathrm{km})^{a}\end{array}$ & $\begin{array}{c}\text { Wheeled } \\
\text { speed per } \\
\text { day }\left(\mathrm{km} \mathrm{h}^{-1}\right)\end{array}$ & $\begin{array}{c}\text { Age } \\
\text { (years) }\end{array}$ & $\begin{array}{c}\text { MWC } \\
\text { experience } \\
\text { (years) }\end{array}$ \\
& $\mathrm{r}$ & $\mathrm{r}$ & $\mathrm{r}$ & $\mathrm{r}$ & $\mathrm{r}$ \\
\hline $\begin{array}{l}\text { WST total performance } \\
\text { score (\%) }\end{array}$ & - & - & - & - & - \\
$\begin{array}{l}\text { Wheeled } \\
\text { distance per day (km) }\end{array}$ & $0.36^{* *}$ & - & - & - & - \\
$\begin{array}{l}\text { Wheeled } \\
\text { speed per day (km } \mathrm{h}^{-1} \text { ) }\end{array}$ & 0.22 & $0.72^{* *}$ & - & - & - \\
$\begin{array}{l}\text { Age (years) } \\
\text { MWC experience (years) }\end{array}$ & -0.15 & -0.01 & -0.10 & 0.17 & - \\
\hline
\end{tabular}

Abbreviations: MWC, manual wheelchair; WST, wheelchair skills test.

acorrelation tests were performed on a transformation of the variable $\left(\log _{10}\right)$ to meet normality assumption.

${ }^{\star} P \leqslant 0.05$

${ }^{*} P \leqslant 0.01$.

$\mathrm{F}(2,47)=0.08, P=0.92$; speed: $\mathrm{F}(2,47)=1.63, P=0.21)$. Table 3 presents correlations between WST total performance score, wheeled mobility at home and in the community, age and MWC experience. There was a significant correlation between WST total performance score and mobility $(r=0.36, P<0.01)$, which suggests that greater MWC skills are slightly associated with higher mobility at home and in the community in terms of daily wheeled distance. The correlation between WST total performance score and daily wheeled distance did not remain significant when controlled for age (partial $r=0.26$, $P=0.07)$. A moderate correlation between age and WST total performance score was also observed $(r=-0.32, P<0.05)$.

Regarding personal characteristics, only employment status revealed significant differences between groups (employed vs not employed) on the total performance score on the WST $(M=77.8 \pm 12.6$ and $85.9 \pm 8.6, \mathrm{~F}(1,51)=6.23, P<0.05)$. No significant differences were found between the groups for other personal characteristics. 
Mean wheeled distance was around $2.5 \mathrm{~km}$ per day at a speed of about $1.7 \mathrm{~km} \mathrm{~h}^{-1}\left(0.47 \mathrm{~m} \mathrm{~s}^{-1}\right)$. We observed a strong correlation between daily wheeled distance and speed $(r=0.72, P<0.01)$, and a moderate to weak correlation between age and these two variables (distance: $r=-0.51, P<0.01$; speed: $r=-0.26, P=0.07$ ).

\section{DISCUSSION}

Overall, the study findings depict the MWC skill profiles of experienced MWC users with SCI and their mobility at home and in the community (distance and speed). We also investigated the relationship between the level of injury, age, MWC experience, and MWC skills and mobility, as well as the relationship between MWC skills and mobility, at home and in the community.

On the basis of total performance and safety scores on the WST and qualitative information collected, participants demonstrated that they had both good MWC skills and good judgment regarding whether they could perform the skills safely or not. As expected, these findings suggest that the level of injury (tetraplegia vs low paraplegia) is related to the MWC skills of people with SCI. Upper body impairments in people with tetraplegia probably limit the execution of some skills. A large proportion of participants with tetraplegia failed the execution of wheelies $(46.2 \%)$, ascending a $15-\mathrm{cm}$ curb $(100 \%)$ or a $10^{\circ}$ incline $(84.6 \%)$. The small WC skills difference between individuals with low and those with high paraplegia is not in agreement with previous results from biomechanical studies, which reported that trunk control has an impact on MWC propulsion and execution of some skills such as ramp ascent. ${ }^{4,18}$ Skills included in the WST might not be able to distinguish between people with differing degrees of trunk control.

The study findings also suggest that younger people have better MWC skills than older people (as capacities in general). Having more experience in using a MWC does not seem to be associated with better skills in people with at least 1 year of experience. These results are in line with other studies that identified personal characteristics (level of injury and age) as having an impact on the MWC skills of people with SCI. ${ }^{9,19}$

Mean daily wheeled distance observed in the study participants is consistent with previous studies reported in the literature, ${ }^{20,21}$ but with lower wheeled speed. Data were collected partly during the cold season (between October 2009 and June 2010), which could help explain this phenomenon. The seasonal influence is quite possible because a majority of the participants (80\%) were tested between November and March, when temperatures were below $0{ }^{\circ} \mathrm{C}$ (in Québec City and Toronto), and there was a mean monthly snowfall of $70 \mathrm{~cm}$ (in Québec City) and $30 \mathrm{~cm}$ (in Toronto) (Canadian Climate Normals 1971-2000, http://climate.weatheroffice.gc.ca). However, because of these environmental conditions, wheeled mobility might be reduced compared with the summer season. The observed mobility values probably reflect 'indoor' rather than 'outdoor' activities. When collecting participants' oral feedback regarding their data-cycle computer logbooks, participants reported that having to propel the WC wearing winter clothes and with snow on the ground discourages them from going outside, and some said that cold temperatures increased their spasms.

Results showed no significant difference in wheeled mobility (distance and speed) at home and in the community depending on the level of the injury (tetraplegia, high and low paraplegia). In addition, the data collection period could have influenced the results. Differences in wheeled mobility between people who have tetraplegia and those with paraplegia may exist during the summer. One of the possible reasons for this difference could be the complete absence of or severely reduced sweating in individuals with tetraplegia, owing to which core and skin temperature increases, and thermal imbalance in both cool and warm conditions increases faster than in individuals with paraplegia, which can lead to thermal injury or autonomic dysreflexia. ${ }^{22}$ Additional analysis is needed to determine seasonal effects on mobility. It is also possible that other environmental barriers (for example, few adapted buildings or no curb cut) are too substantial to allow individuals with better MWC skills to have greater wheeled mobility. The participants' age was negatively associated with wheeled mobility at home and in the community. These results partially correspond with findings of previous studies that used questionnaires to assess social participation, and suggest that both age and level of injury were associated with participation of individuals with SCI. ${ }^{1,9}$ One study looked at the results for each social participation domain separately and identified that only level of injury was associated with the mobility domain. ${ }^{1}$ Other personal factors such as employment status, fewer secondary complications and better physical fitness could also have an impact on home and community mobility.

As expected, there was a relationship between MWC skills and mobility, at home and in the community (wheeled distance), but this relationship might be due to a stronger correlation between age and these two variables. Despite the non-significant correlation between mobility and MWC skills after controlling for age, owing to the lack of statistical power, such an association remains possible and should be considered. In our opinion, given the potential contribution of many environmental and personal factors to WC mobility, any single factor showing a correlation of $\sim 0.2$ with mobility variables must be considered as an important contributor to such variables. Moreover, one could argue that the effect of age could be reduced with formal MWC skills training.

\section{LIMITATIONS}

As mentioned in the discussion, one limitation of this study was the seasonal effect (winter period), which could have had a considerable influence on the mobility data collected. As this study is considered as a first step towards demonstrating the importance of improving MWC skills to ensure optimal mobility in the community, ideally we should have eliminated this major environmental barrier and focused on the impact of personal factors. Seasonal effects on mobility could be taken into consideration in the design and analysis of future studies. Another limitation is that information about level of injury was selfreported by participants. It was not possible to collect this information from medical records. Injury information given by participants might be wrong, owing to changes after discharge (or last evaluation) or their lack of precise information about injury severity. Some limitations could also be associated with the commercial cycle computer system used to measure wheeled mobility. As it has never been used in such a study, the system was pretested to ensure the measures were accurate. Distance data of the cycle computer were taken several times and compared with known distances. Moreover, distance results corresponding to the literature suggested sufficient accuracy for an initial investigation. In addition to the mean wheeled distance per day recorded, the participant's logbook could have provided important information concerning the type of activities performed by the person every day. This strategy could also help validate the wheeled mobility results obtained.

\section{CONCLUSION}

These results suggest that the level of injury and age are related to MWC skills. Age is also related to wheeled daily distance, but there is no difference in home and community mobility (distance and speed) 
between people with different levels of injury. MWC skill scores are correlated to daily wheeled distance at home and in the community, but are not significant when controlling for age. Further investigation will be done regarding the relationship between level of injury, MWC skills, MWC confidence and social participation.

\section{CONFLICT OF INTEREST}

The authors declare no conflict of interest.

\section{ACKNOWLEDGEMENTS}

This study was sponsored by Ontario Neurotrauma Foundation (ONF), the Quebec Rehabilitation Research Network (REPAR), the Centre de recherche en réadaptation et intégration sociale (CIRRIS), the Fondation pour la recherche sur la moelle épinière and the Social Sciences and Humanities Research Council (SSHRC) of Canada.

1 Noreau L, Fougeyrollas P. Long-term consequences of spinal cord injury on social participation: the occurrence of handicap situations. Disabil Rehabil 2000; 22: 170-180.

2 Fougeyrollas P, Bergeron H, Cloutier R, Côté J, St-Michel G. Classification québécoise Processus de production du handicap. RIPPH: Lac St-Charles, 1998.

3 Kilkens OJ, Dallmeijer AJ, Nene AV, Post MW, van der Woude LH. The longitudinal relation between physical capacity and wheelchair skill performance during inpatient rehabilitation of people with spinal cord injury. Arch Phys Med Rehabil 2005; 86 1575-1581.

4 Gagnon D, Verrier M, Masani K, Nadeau S, Aissaoui R, Popovic M. Effects of trunk impairments on wheelchair propulsion and wheelchair-related activities among individuals with spinal cord injury: a brief overview and future challenges. Top Spinal Cord Inj Rehabil 2009; 15: 59-70.

5 van der Woude LH, de Groot S, Janssen TW. Manual wheelchairs: research and innovation in rehabilitation, sports, daily life and health. Med Eng Phys 2006; 28: 905-915.

6 Lidal IB, Huynh TK, Biering-Sorensen F. Return to work following spinal cord injury: a review. Disabil Rehabil 2007; 29: 1341-1375.

7 van Velzen JM, de Groot S, Post MW, Slootman JH, van Bennekom CA, van der Woude LH. Return to work after spinal cord injury: is it related to wheelchair capacity at discharge from clinical rehabilitation? Am J Phys Med Rehabil 2009; 88: 47-56.
8 Wheelchair Skills Training Program (WSTP). Version 4.1. Wheelchair Skills Training Program (WSTP) Manual 2010. http://www.wheelchairskillsprogram.ca.

9 Kilkens OJ, Post MW, Dallmeijer AJ, van Asbeck FW, van der Woude LH. Relationship between manual wheelchair skill performance and participation of persons with spinal cord injuries 1 year after discharge from inpatient rehabilitation. J Rehabil Res Dev 2005; 42(Suppl 1): 65-73.

10 Post MW, van Asbeck FW, van Dijk AJ, Schrijvers AJ. Services for spinal cord injured: availability and satisfaction. Spinal Cord 1997; 35: 109-115.

11 Jenkins S. Wheelchair Training Provision by NHS Wheelchair Services. Whizz-Kidz: London, 2002.

12 Karmarkar AM, Collins DM, Wichman T, Franklin A, Fitzgerald SG, Dicianno BE et al. Prosthesis and wheelchair use in veterans with lower-limb amputation. J Rehabil Res Dev 2009; 46: 567-576.

13 Best KL, Kirby RL, Smith C, MacLeod DA. Wheelchair skills training for communitybased manual wheelchair users: a randomized controlled trial. Arch Phys Med Rehabil 2005; 86: 2316-2323.

14 Kirby RL, Mifflen NJ, Thibault DL, Smith C, Best KL, Thompson KJ et al. The manual wheelchair-handling skills of caregivers and the effect of training. Arch Phys Med Rehabil 2004; 85: 2011-2019.

15 Coolen AL, Kirby RL, Landry J, MacPhee AH, Dupuis D, Smith C et al. Wheelchair skills training program for clinicians: a randomized controlled trial with occupational therapy students. Arch Phys Med Rehabil 2004; 85: 1160-1167.

16 Lindquist N, Loudon P, Magis T, Rispin J, Kirby R, Manns P. Reliability of the performance and safety scores of the wheelchair skills test version 4.1 for manual wheelchair users. Arch Phys Med Rehabil 2010; 91: 1752-1757.

17 Fliess-Douer O, Vanlandewijck YC, Lubel Manor G, Van Der Woude LH. A systematic review of wheelchair skills tests for manual wheelchair users with a spinal cord injury: towards a standardized outcome measure. Clin Rehabil 2010; 24: 867-886.

18 Howarth SJ, Polgar JM, Dickerson CR, Callaghan JP. Trunk muscle activity during wheelchair ramp ascent and the influence of a geared wheel on the demands of postural control. Arch Phys Med Rehabil 2010; 91: 436-442.

19 Kilkens OJ, Dallmeijer AJ, Angenot E, Twisk JW, Post MW, van der Woude LH. Subjectand injury-related factors influencing the course of manual wheelchair skill performance during initial inpatient rehabilitation of persons with spinal cord injury. Arch Phys Med Rehabil 2005; 86: 2119-2125.

20 Wilson SK, Hasler JP, Dall PM, Granat MH. Objective assessment of mobility of the spinal cord injured in a free-living environment. Spinal Cord 2008; 46: 352-357.

21 Cooper RA, Tolerico M, Kaminski BA, Spaeth D, Ding D, Cooper R. Quantifying wheelchair activity of children: a pilot study. Am J Phys Med Rehabil 2008; 87: 977-983.

22 Price MJ. Thermoregulation during exercise in individuals with spinal cord injuries. Sports Med 2006; 36: 863-879. 